\title{
The Past in the Present of Syria
}

The past takes an important role in our present life. The peoples or individuals use the past to prove propriety of different things such as lands and houses. Moreover, the past is used to legitimate and found states. Museums are the main place where we can see the past displayed front of our eyes by materials. Then, the history textbooks, in the schools, offer the knowledge of all the people about the past. Accordingly, a national identity will be formed.

So, this paper will highlight on the Syrian museums, its foundation and role. Also, a general view on the history textbooks in the Syrian schools will be given. In addition, some comparisons with Saudi Arabia will be made. 